6.

Derecho económico 



\title{
SERVICIO PÚBLICO Y SECTOR ELÉCTRICO. EVOLUCIÓN EN EUROPA DESDE LA EXPERIENCIA ESPAÑOLA
}

["Public Service and Electric Utilities

Development in Europe Starting from the Spanish Experience"]

\author{
Alberto Olivares Gallardo* \\ Universidad Católica de Temuco, Chile
}

\begin{abstract}
Resumen
Se analiza la evolución que ha tenido la institución del servicio público, desde su nacimiento en el siglo XIX, hasta su estadio actual, en que la liberalización de los servicios económicos promovida por la Unión Europea ha alterado su naturaleza, en el sentido de integrar el paradigma del mercado como medio idóneo de asignación de recursos a la concepción de prestación pública de determinados servicios a la comunidad en condiciones de calidad, continuidad y a precios accesibles. El estudio se propone analizar la relación del servicio público con un sector económico concreto: el eléctrico, para la
\end{abstract}

\begin{abstract}
Analysis of the development of the public utilities board, from its origin in the $19^{\text {th }}$ century, until its current status, when the liberalization of the economic services boosted by the European Union has altered its nature by incorporating the market paradigm as an ideal means to allocate resources to the idea of rendering certain state-owned services to the community with quality, continuity and at affordable prices. This study is aimed at analyzing the relationship of the public services with a specific economic area: electric utilities, for the European
\end{abstract}

RECIBIDo el 30 de octubre y ACEPTADo el 15 de noviembre de 2012.

* Profesor de Derecho público de la Universidad Católica de Temuco. Investigador responsable del Grupo de Investigaciones Jurídicas de la Universidad Católica de Temuco. Dirección postal: Manuel Montt 56, Temuco, Chile. Correo electrónico: alberto.olivares@uct.cl 
realidad europea, y desde una mirada de la realidad española

Palabras Clave Servicio público - Sector eléctrico. reality, from an insight into the Spanish experience.

KEYWORDS

Public Services - Electric utilities.

\section{INTRODUCCIÓN}

La organización del sector público eléctrico chileno presenta similitudes con la construcción que ha realizado la Unión Europea para la industria energética de los Estado miembros ${ }^{1}$. La liberalización del sector eléctrico que se promueve con gran entusiasmo por la Unión Europea desde los años noventa ha tenido su equivalente en la legislación eléctrica nacional desde la década de los ochenta.

En Chile "estas actividades son desarrolladas por empresas que son controladas en su totalidad por capitales privados, mientras que el Estado ejerce funciones de regulación, fiscalización y planificación"2. Este modelo es el utilizado por la gran mayoría de los Estados miembros de la Unión Europea. Aún existe una prestación pública del servicio eléctrico en algunos países como Francia e Italia, pero que poco a poco han ido aceptando las directrices comunitarias y han accedido a introducir competencias en sus mercados nacionales, compitiendo sus empresas públicas eléctricas (EDF y ENEL, respectivamente) con las empresas privadas de los Estados miembros de la Unión Europea.

No obstante, en este mercado eléctrico liberalizado, en que el Estado ha dejado de suministrar directamente electricidad a los usuarios, persiste la idea de servicio público, que se expresa en la calificación de servicio público que realiza el Decreto con fuerza de ley $\mathrm{N}^{\circ}$ 4/20018 de 2007, a la actividad eléctrica.

No se trata de una calificación a la actividad eléctrica en general, sino que está referida, más bien, a dos actividades en concreto. Señala el artículo 7 inciso $1^{\circ}$ de esta Ley: "Es servicio público eléctrico el suministro que efectúe una empresa concesionaria de distribución a usuarios finales ubicados en sus zonas de concesión, o bien a usuarios ubicados fuera de dichas zonas, que se conecten a las instalaciones de la concesionaria mediante líneas propias o de

\footnotetext{
${ }^{1}$ Un interesante estudio sobre el sector público eléctrico chileno es el que realiza Vergara Blanco, Alejandro, Concepto, elementos y principios del servicio público eléctrico, en Revista de Derecho de la Universidad de Concepción, 212 (2002) 2.

${ }^{2}$ Evans Espiñeira, Eugenio - Seeger Caerols, María, Derecho eléctrico, (Santiago de Chile, LexisNexis, 2006), p. 1.
} 
terceros". El inciso tercero de la misma norma indica: "Asimismo, es servicio público eléctrico el transporte de electricidad por sistemas de transmisión troncal y subtransmisión".

El sector eléctrico chileno está integrado por tres actividades: la generación, el transporte y la distribución. La primera es una actividad de libre concurrencia, es decir, en que operan los principios de la libre competencia. En cambio, el transporte y la distribución son servicios públicos para la legislación chilena, pero cuya prestación, en un marco liberalizado, la realizan los particulares a través de un título jurídico habilitante: la concesión, que genera al concesionario entre muchas obligaciones la de servicio en condiciones de calidad, continuidad y precios accesibles; pero como contrapartida le crea un derecho esencial para nuestro modelo: la exclusividad dentro de su zona de concesión.

La configuración del transporte y la distribución como servicios públicos tiene que ver con la tendencia a configurarse estas actividades en monopolio natural. En general, todas las actividades de redes, y la eléctrica lo es, suelen constituirse como monopolios naturales. Aquí radica la dificultad de introducir competencia en el transporte y la distribución y una explicación rápida de porqué la legislación eléctrica chilena, proclive a la liberalización del sector, desde 1982, ha decidido dar la categoría de servicio público a la distribución primero, y al transporte con modificaciones posteriores a la Ley general del sector eléctrico.

En este contexto del modelo eléctrico chileno, el presente trabajo pretende mostrar la realidad del sector eléctrico en la Unión Europea -desde la especial mirada de la experiencia española-, que ha ido moldeando las legislaciones de los Estados miembros, obligándolos a integrar diversas técnicas de liberalización de sus industrias energéticas, incluso para las actividades de transporte y distribución, que podrían resultar útiles a la hora de lograr introducir competencia en la distribución del servicio público eléctrico en nuestro país.

Esta revisión que se propone, se realiza tomando como punto de partida la institución del servicio público y su intensa relación con el sector eléctrico, para pasar a continuación a un examen de la transformación que ha tenido el servicio público desde el surgimiento de la Comunidad Europea (hoy Unión Europea) y su incidencia sobre la industria energética.

\section{INTERVENCIÓN ESTATAL EN LAS ACTIVIDADES ECONÓMICAS DE INTERÉS PÚBLICO}

La titularidad pública de la actividad económica justifica que el Estado pueda ostentar las potestades de planificación, dirección, inspección, vi- 
gilancia y control, que ejercita mediante organismos o empresas públicas (monopolio público), por la gestión indirecta (concesión) o regulando intensamente a los operadores privados cuando permite que éstos realicen la prestación de actividades económicas de interés público (monopolio u oligopolio privado) $)^{3}$.

Estas potestades de las Administraciones públicas, pueden ser desarrolladas a través de diversas modalidades de actuación administrativa, que podemos clasificar de la siguiente forma ${ }^{4}$ :

i) Actividad de policía o limitación, en que la Administración interviene, y en ocasiones muy seriamente, en la actividad de los ciudadanos, a través de fórmulas o técnicas (principalmente la autorización, también denominada licencia o permiso) que de algún modo condicionan o delimitan el ejercicio de sus derechos subjetivos e intereses, por razones de interés general. Se trata de una actividad de limitación que las Administraciones llevan a cabo con el objeto de proteger el libre ejercicio de los derechos y libertades y la garantía de la seguridad ciudadanas.

ii) Actividad de fomento, a través de la cual se ofrecen estímulos positivos a los ciudadanos y empresas que satisfacen determinados fines establecidos previamente en atención al interés general ${ }^{6}$.

iii) Actividad prestacional, en que destaca la idea de servicio público, que será estudiado en el siguiente apartado. Por ello, y de manera general que "el contenido o concepto de servicio público se suele identificar con una actividad de prestación efectiva a los ciudadanos por parte de las Administraciones públicas, en forma y condiciones legalmente establecidas, aunque la gestión concreta pueda encomendarse a terceros"

${ }^{3}$ De la Cruz Ferrer, Juan, La liberalización de los servicios públicos y el sector eléctrico. Modelos y análisis de la Ley 54/1997 (Madrid, Marcial Pons, 2005), pp. 349350.

${ }^{4}$ En este punto, seguiremos a Bermejo Vera, José, Derecho administrativo. Parte especial ( $7^{\text {a }}$ edición, Cizur Menor, Aranzadi, 2009), pp. 52-71, quien realiza la clasificación de las actividades administrativas que aquí se propone, en. Sobre el mismo tema, véase PARAda, Ramón, Derecho administrativo. Parte general (16a edición, Madrid, Marcial Pons, 2007), I, pp. 337-498. También, Parejo Alfonso, Luciano y otros, Manual de Derecho administrativo (5a edición, Barcelona, Ariel, 1998), I, pp. 441547.

${ }^{5}$ La mayor parte de la actuación del Estado sobre el sector eléctrico en un primer periodo, fue llevada a cabo principalmente a través de la actividad de policía.

${ }^{6}$ Un claro ejemplo de la actividad de fomento en la actividad energética lo observamos en los estímulos que ha recibido la industria eléctrica renovable, en la Ley $\mathrm{N}^{\circ}$ 20.257, de 2008, que introduce modificaciones a la Ley General de servicios eléctricos respecto de la generación de energía eléctrica con fuentes de energías renovables no convencionales.

${ }^{7}$ Bermejo Vera, Derecho, cit. (n. 4), p. 61. 
iv) Actividad económica directa, referida a la producción o prestación de servicios de carácter económico.

Todas estas formas de intervención han sido utilizadas por el Estado en diversos periodos históricos de su relación con los servicios económicos en general. En cuanto a la industria eléctrica en particular, el sector ha tenido una intensa relación con el Estado, atendidas principalmente dos características particulares: en primer lugar, la importancia estratégica, que desde el comienzo los Estados ha asignado a la energía ${ }^{8}$; segundo, el carácter de monopolio natural de la actividad eléctrica, por tratarse de una industria de redes.

Sobre este último punto-el desarrollo que históricamente ha tenido el sector eléctrico como monopolio natural-, no se profundizará mayormente, por no tratarse del objeto de estudio. Solo diremos que esta característica ha influido decisivamente en el desarrollo del servicio público como forma de intervención del Estado en el sector?.

El proceso de publificación de las actividades económicas esenciales -que trataremos con mayor profundidad en los apartados siguientes- cuyo mayor auge en Europa podemos situar entre la década de los treinta hasta los ochenta, se sintió especialmente en la industria eléctrica. En la mayoría de los países, el sector eléctrico fue calificado como servicio público ${ }^{10}$, asumiendo el Estado su actividad, de manera directa o indirecta, entregando la

${ }^{8}$ En este sentido, expresa Martín Mateo, Ramón, Nuevo Derecho energético (Madrid, Instituto de Estudios de Administración Local, 1982), p. 9, que: "A medida que se progresa civilizatoriamente adoptándose formas de organización social que limitan o condicionan el ejercicio espontáneo de la fuerza individual, la energía va a aparecer constantemente conectada con quienes controlan el aparato institucional". En el mismo sentido, Cremades, Javier - Rodríguez-Arana, Jaime, Perspectivas del Derecho de la energía en España y en la UE, en Santos Rech, Miriam - Cameo Bel, Fernando (coordinadores), Derecho de la energía, (Madrid, Wolters Kluwer, 2006), pp. 57 ss. También, Álvarez García, Vicente - Duarte Martínez, Rafael, Administración pública y electricidad, (Madrid, Civitas, 1997), p. 17.

${ }^{9}$ En este sentido, cabe tener presente que las formas de intervención por parte del Estado para reducir los monopolios, en general, son los siguientes: i) gravar los monopolios con impuestos; $i$ ) controlar los precios; $i$ ii) adquirir la propiedad de los monopolios, transformando las empresas monopólicas en empresas estatales; $i v$ ) regular el mercado; y $v$ ) estableciendo una política antimonopolios. En tal sentido, véase: Samuelson, Paul - Nordhaus, William, Economía (13 a edición, traducción castellana de Luis Toharia y María Esther Tabasco, Madrid, McGraw-Hill, 1990), p. 681. Similar enumeración realiza, FisCHER en: FisCher, Stanley - Dornb u S CH, Rudiger

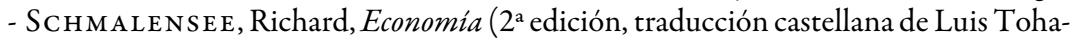
ria y María Esther Tabasco, Madrid, McGraw-Hill, 2005), pp. 74-80.

${ }^{10} \mathrm{La}$ calificación como servicio público de ciertas actividades, entre ellas la eléctrica, es una tradición propia del Derecho continental europeo (Francia, España, Italia, Bélgica, etc.). En Gran Bretaña y los EE.UU. estas actividades responden a la denominación 
explotación a particulares en monopolio - a través de una concesión para los países de tradición jurídica continental europea- ${ }^{11}$. Por su parte, el mundo anglosajón desarrollo la doctrina de las "public utilities" o "utility services", más cercana a la organización actual de los servicios públicos en un contexto de liberalización de los servicios económicos esenciales ${ }^{12}$.

Si el Estado asumía la actividad energética por sí misma, su posición monopólica no se cuestionaba, entre otros motivos, por representar los intereses generales de la sociedad. Cuando la gestión era adjudicada a empresas privadas, a través de concesiones, la posición monopólica era asumida por ésta, y el Estado imponía obligaciones de servicio público a cambio de otorgar (o permitir) exclusividad en el suministro en determinados territorios.

En cuanto a la importancia estratégica de la energía para los Estados, es preciso apuntar que el vertiginoso avance de la sociedad desde que conocemos la electricidad hasta nuestros días, ha impulsado al Estado estrechar lazos con la actividad energética ${ }^{13}$.En el mismo sentido, la dependencia del mundo moderno de la energía, al punto de no concebirse un modelo de desarrollo sin un consumo energético masivo, ha obligado a la Administración

de "public utilities", y presentan como principal característica la de ser monopolios naturales. Sobre este tema, se hablará con mayor atención en los apartados siguientes.

${ }^{11}$ García de Enterría - Fernández, Curso de Derecho administrativo (15a edición, Madrid, Civitas, 2011), p. 762, señalan que: "El contrato de concesión de obra pública ha sido una figura clave en el desarrollo del Derecho Administrativo desde el siglo XIX hasta hoy. Partiendo del prejuicio liberal contrario a la capacidad mercantil e industrial de la Administración (y también por su falta de generar recursos para realizar grandes inversiones), la concesión venía a resolver el problema de la creación y/o gestión de servicios públicos cuya explotación requería una técnica empresarial mediante la interposición de una empresa privada. Se desdoblaba así, por una parte, la titularidad del servicio, que retiene en todo caso la Administración concedente, y por otra, la gestión de un servicio de naturaleza predominantemente económica (o que 'no impliquen ejercicio de la autoridad inherente a los poderes públicos': artículo 251.1, in fine, LCSP), el cual se entrega a un concesionario privado que es, por tanto, quien hace la inversión necesaria mediante la construcción de la obra pública que ha de servir como infraestructura del servicio y la adquisición del material que resulte preciso para la explotación de servicio público correspondiente. Esta fuerte inversión se retribuiría y amortizaría mediante las tarifas que la concesión le habilitaba a percibir de los usuarios".

${ }^{12} \mathrm{~A}$ pesar que se hablará más adelante de estas instituciones típicamente anglosajonas, se puede dejar aquí establecido que la nomenclatura "public utilities" es propiamente norteamericana, y las utility services es una denominación del Derecho inglés. Cfr. Garne R, John, Administrative Law (Londres, Butterworths, 1963), p. 375.

${ }^{13}$ Nos referimos no solo al avance tecnológico, que nos ha llevado a construir una sociedad devoradora de energía, sino también otros avances de tipo social o de derechos fundamentales, que ha tendido a relacionar la calidad de vida de las personas con mayores índices de consumo energético. 
a idear diversos instrumentos de intervención administrativa sobre el sector energético en general, y el eléctrico en particular, que han sido empleados en distintas épocas, que -siguiendo el modelo español- estudiaremos a continuación.

\section{LA ADMINISTRACIÓN Y LA NACIENTE INDUSTRIA ENERGÉTICA}

La revolución industrial significó, en materia energética, un cambio cultural esencial. El modelo energético preindustrial, fundado principalmente en las denominadas fuentes energéticas animadas -el hombre y los animales-, dio paso a un modelo energético caracterizado por la utilización cada vez mayor de las fuentes energéticas inanimadas, es decir, aquellas distintas del hombre y los animales ${ }^{14}$.

Las exigencias de la naciente industria de finales del siglo XVIII, provocaron una verdadera revolución en el mundo energético. De forma sucinta, cabe señalar que el descubrimiento de la máquina de vapor en 1769 , dio inicio a la época del carbón como materia prima básica, hasta que en el último tercio del siglo XIX tuvo lugar el nacimiento de la época de la electricidad, producida en un primer momento desde el carbón y el agua ${ }^{15}$.

Desde la llegada de la electricidad como fuente energética hasta su posicionamiento como una fuente de energía esencial para la sociedad, no hubo de pasar mucho tiempo; a principios del siglo XX la electricidad comienza a considerarse como una actividad industrial en sentido pleno y en el segundo decenio del referido siglo, el sector eléctrico asienta las bases de la vigorosa industria que hoy conocemos ${ }^{16}$.

${ }^{14}$ En el modelo energético preindustrial, solo a menor escala se utilizaban otras fuentes energéticas como la biomasa o el agua.

${ }^{15}$ Sobre los antecedentes históricos y regulatorios de la actividad eléctrica en España, véanse: Nebreda Pérez, Joaquín, Distribución eléctrica. Concurrencia de disciplinas jurídicas (Madrid, Civitas, 1999), pp. 49 ss.; SALAS Hernández, Javier, Régimen jurídico-administrativo de la energía eléctrica (Bolonia, Publicaciones del Real Colegio de España, 1977), pp. 31 ss.; Gimeno Felıú, José, El sector eléctrico como servicio público (Madrid, Civitas, 1994), pp. 35 ss.

${ }^{16}$ Nebreda Pérez, Joaquín, cit. (n. 15), p. 50. Sobre el mismo punto, Parejo Alfonso, Luciano, Lecciones de Derecho administrativo. Orden económico y sectores de referencia (Valencia, Tirant lo Blanch, 2010), p. 566, apunta: "La intervención pública en el sector de la energía eléctrica se desarrolla, al hilo de su creciente importancia, desde finales del S. XIX sobre la base de la titularidad demanial de los bienes que ha de utilizar el suministro y, por tanto, la concesión administrativa; base a partir de la cual se consolidan progresivamente las competencias tanto de la Administración general (primero con la concesión de aprovechamientos hidráulicos y luego, desde comienzos del siglo XX, concesiones e interposición del imperium para asegurar 
La actividad eléctrica, en general en Europa, fue realizada desde sus inicios por empresas privadas, en un ámbito de libertad empresarial y la intervención del Estado se limitaba en un primer momento temas concretos, referidos a la tributación de la incipiente industria, la servidumbre de paso de la red de transporte de electricidad, cuestiones de seguridad de las instalaciones, y la protección de los usuarios cuando surgen los primeros abusos de las empresas ${ }^{17}$.

En este punto es necesario tener presente que los Estados europeos del siglo XIX, en mayor o menor medida, estaban imbuidos ideológicamente de las ideas liberales de la economía política clásica de Smith, Malthus y Ricardo, y tenían una concepción restrictiva de la intervención estatal en la actividad económica, limitada a garantizar la seguridad (interior y exterior) en la sociedad, dotarla de una Administración de Justicia, y realizar y conservar ciertas obras públicas de interés común ${ }^{18}$.

El Estado propugnaba el "laissez-faire", doctrina en que la Administración toma una actitud pasiva respecto de la vida económica, en favor de la libertad de industria y comercio, interviniendo de manera específica cuando surgieran problemas de seguridad para la comunidad o para el desarrollo de obras que los particulares no quisiesen o no pudiesen asumir.

En lo concerniente a la energía, debemos tener en cuenta lo que apunta Nebreda Pérez, quien ilustra - concerniente a España- que: "Desde los albores del suministro eléctrico, la Administración tuvo claro que la nueva actividad industrial era un importante centro recaudatorio, que requería de alguna protección en favor de sus consumidores, y que su implantación, socialmente beneficiosa, tenía evidentes dificultades a superar"19. Se comenzó a realizar, por tanto, una intervención administrativa casuística, sectorial y desorganizada.

las líneas de transporte) como de la local (concesiones sobre la base de la competencia en materia de alumbrado público)".

${ }^{17}$ En concreto, para el caso español, podemos señalar el RD 28-V-1896, sobre contribución industrial; la Ley de 22 de junio de 1898, que crea el impuesto al consumo de fluido eléctrico; la Ley de 23 de marzo de 1900, de servidumbre forzosa de paso de corrientes eléctricas, desarrollada por el Real Decreto de 15 de junio de 1901; la Ley de expropiación forzosa, de 23 de marzo de 1900; el Real Decreto de 25 de enero de 1901, que regula los contadores eléctricos; el Real Decreto de 22 de noviembre de 1912 que crea la Comisión Permanente Española de Electricidad; entre otros. Para profundizar sobre la legislación eléctrica de la época, véanse Gimeno Feliú, José, cit. (n. 15), pp. 35 ss.; Trillo-Figueroa Martínez-Conde, Jesús - López-Jurado Escribano, Francisco, La regulación del sector eléctrico (Madrid, Civitas, 1996), pp. 550 ss.

${ }^{18}$ Véase Muñoz MaCha do, Santiago, Tratado de Derecho administrativo y Derecho público General (3a edición, Madrid, Iustel, 2011), I, pp. 896 ss.

${ }^{19}$ Nebreda PÉrez, Joaquín, cit. (n. 15), p. 51. 
Con el paso del tiempo, sin embargo, "la complejidad de los medios técnicos, la relevancia económica de la actividad que se lleva a cabo a través de ellos y el aumento constante de los usuarios afectados -industriales y simples particulares- hace que la Administración tome conciencia de la necesidad de reglamentar el servicio de una manera global y unitaria, por encima de las concreciones singulares que representan las correspondientes concesiones y autorizaciones" ${ }^{20}$.

En esta primera etapa, la intervención del Estado español se realizaba principalmente a través de la concesión demanial ${ }^{21}$, tanto de las aguas públicas como de las instalaciones y redes de transporte de la electricidad. En este contexto, se puede identificar una actividad eléctrica de carácter principalmente municipal.

Por ello, la primera intervención administrativa se dio también en el ámbito local. Así, se puede observar lo que ocurría en Inglaterra, donde hasta finales del siglo XIX funcionaba la regla de la no intervención del Gobierno en los asuntos locales, y la industria eléctrica era un asunto local.

Lo mismo sucedía en Alemania, donde las empresas eléctricas tenían inicialmente un carácter local, y los municipios poseían amplias facultades en la ordenación del sector, sistema que en esencia persiste ${ }^{22}$.

En España ocurría una situación similar. En la época de la implantación del sector eléctrico en la vida del país, a finales del siglo XIX, como destaca Muñoz Machado, las competencias sobre estas industrias eléctricas eran fundamentalmente municipales. Los ayuntamientos mantuvieron en España, como es común en otros Estados europeos, posiciones muy relevantes en el desarrollo inicial del suministro eléctrico. "Es en las ciudades donde se lleva a cabo lo fundamental del suministro de electricidad y, por tanto, debe quedar su control en manos municipales"23.

Por estas razones, y pese a la concepción no intervencionista imperante en esta primera época de la electricidad, según recuerda Nebreda Pérez para el caso español, hay intervención local, pero también de la Administración central del Estado ${ }^{24}$.

La intervención local se da principalmente a través de las leyes municipales de 1870 y 1877 que hacen referencia a la competencia municipal en el alumbrado, así como en razón de la potestad de policía industrial, que tienen

${ }^{20}$ Salas Hernández, Javier, cit. (n. 15), p. 31.

${ }^{21}$ Para la doctrina española la concesión demanial es aquella que recae sobre bienes de dominio público.

${ }^{22}$ Muñoz MaChado, Santiago, Tratado, cit. (n. 16), pp. 17-19. Véase también, Salas Hernández, Javier, cit. (n. 13), pp. 41-57.

${ }^{23}$ Muñoz Machado, Santiago, Tratado, cit. (n. 18), p. 14.

${ }^{24}$ Nebreda PÉrez, Joaquín, cit. (n. 15), pp. 52 ss. 
los ayuntamientos, y de demanialidad de las vías públicas urbanas, a través de las cuales habría de realizarse el tendido eléctrico (licencias urbanísticas, así como permisos de uso de suelo público municipal).

Por su parte, hubo competencias asumidas por el Estado en materia de autorizaciones de instalaciones eléctricas (Real Decreto de 14 de marzo de 1890), de servidumbres forzosas (Ley de 23 de marzo de 1900), de definición de normas técnicas y de seguridad (Real Decreto de 7 de octubre de 1904),y de potestad tarifaria (Real Ordenanza de 14 de agosto de 1920 y Ordenanza Ministerial de 12 de diciembre de 1923) ${ }^{25}$.

En definitiva, la intervención del Estado en el sector de la energía, comenzó como una actividad de policía sobre la actividad privada en el campo eléctrico, habida consideración del postulado liberal dominante en la época, sumado a la "incapacidad de los entes públicos para realizar actividades empresariales" ${ }^{\prime 26}$.

\section{LA INDUSTRIA ELÉCTRICA Y EL SERVICIO PÚBLICO. ASUNCIÓN DEL ESTADO PRESTACIONAL}

Paralelo a la creciente intervención administrativa que soportaba la actividad eléctrica, irrumpía en la actividad de la Administración una nueva forma de relación entre el Estado y los servicios económicos esenciales para la comunidad: el servicio público.

La implantación del régimen liberal en los Estados europeos de finales del siglo XVIII y principios del XIX, significó que estos comenzaran a realizar actividades prestacionales en sentido estricto: esto es, servicios públicos uti singuli, destinados a prestar utilidad a personas concretas y determinadas (sin perjuicio, claro está, de su utilidad social genérica) ${ }^{27}$. Esta actividad prestacional concreta y de naturaleza singular, que conllevaba una finalidad colectiva, fue el germen del servicio público, que se expandió por toda la Europa continental y Latinoamérica, desde finales del siglo XIX, hasta nuestros días.

\footnotetext{
${ }^{25}$ Sobre estos temas, véanse Nebreda PÉrez, Joaquín, cit. (n. 15), pp. 52 ss.; SALAS HeRnández, Javier, cit. (n. 15), pp. 36 ss.

${ }^{26}$ Santamaría Pastor, Juan, Principios de Derecho administrativo general (Madrid, Iustel, 2004), II, p. 297.

${ }^{27}$ En el mismo sentido, GonZÁlez-Varas IbáÑez, Santiago, Tratado de Derecho administrativo. Derecho administrativo económico (Cizur Menor, Aranzadi, 2008), IV, p. 91, expresa que los servicios públicos "en principio, están basados en una concepción jurídica según la cual el poder público puede asumir un determinado sector o actividad (mediante un acto llamado publicatio) con el fin de satisfacer necesidades básicas de la población que todo el mundo debe tener a su alcance, tales como el transporte, el correo, el teléfono, la luz, el agua, el transporte, etc.”
} 
Este Estado liberal dio paso, por tanto, a un Estado prestacional, caracterizado, siguiendo la clasificación de Ariño, como titular de actividades, fundado en el interés público de una actividad considerada esencial para la sociedad y en la cual existen fallos de mercado, que le permiten al Estado reservarse la titularidad de una actividad como servicio público. El ejercicio de dicha actividad puede realizarla por gestión indirecta a través de la iniciativa privada (mediante concesión), o por gestión directa ${ }^{28}$.

Este fenómeno de asunción de actividades por parte del Estado, tuvo lugar en tres etapas $\left.{ }^{29}: i\right)$ La asunción de servicios asistenciales; ii) La creación de infraestructuras; y iii) La realización de actividades empresariales.

La actividad asistencial estaba radicada en la Iglesia y otras organizaciones sociales durante el Antiguo Régimen. Entre los servicios sociales asumidos por la Iglesia y organizaciones no estatales, en España hasta finales del XVII, no figuraba el aprovisionamiento de electricidad, sino que estaban más bien referidos a la enseñanza, la salud, la asistencia social, entre otros. Por ello, no resulta relevante este periodo inicial de la actividad prestacional del Estado para el tema que se estudia ${ }^{30}$.

En cambio, fue en la segunda fase de la actividad prestacional del Estado, esto es, cuando se hizo necesario el impulso de grandes infraestructuras que constituían (y constituyen) la base física de otros tantos servicios, que el Estado promovió o desarrolló por sí mismo la producción y distribución de electricidad ${ }^{31}$.

De la misma forma, también existió una estrecha relación entre Estado y sector eléctrico en la tercera fase de las actividades prestacionales del Estado

${ }^{28}$ Ariño Ortiz, Gaspar - López de CASTro, Lucía, El sistema eléctrico español: Regulación y competencia (Madrid, Montecorvo, 1998), pp. 38-41, clasifican las formas tradicionales de actuación administrativa en la actividad económica en los siguientes tipos: a) Estado regulador: el Estado dicta normas ordenadoras o configuradoras de la vida social y económica. Esta regulación puede ser $i$ ) básica y general; ii) administrativa general, de policía y buen gobierno; iii) regulación económica stricto sensu; $b$ ) Estado promotor: se trata de la actividad administrativa de fomento; $c$ ) Estado titular de actividades, según ya hemos visto; $d$ ) Estado propietario: asume la propiedad de empresas y tiene presencia directa en los mercados de bienes y servicios; y e) Estado planificador: a través de técnicas de previsión y planificación indicativa, el Estado pretende la conformación de la realidad social. Véase

${ }^{29}$ Para profundizar sobre este punto, véanse: MuÑ Oz MACHA DO, Santiago, Tratado, cit. (n. 18), pp. 147 ss.; GonZález-VAras IbáÑ̃EZ, Santiago, cit. (n. 27), pp. 91 ss.; Bermejo Vera, José, Derecho, cit. (n. 4), pp. 145 ss.

${ }^{30}$ No obstante, un riguroso estudio de este tema puede encontrarse en MUÑoZ Machado, Santiago, Tratado, cit. (n. 18), pp. 150 ss.

${ }^{31}$ Sobre este tema, véase Nebreda Pérez, Joaquín, cit. (n. 15), pp. 55 ss. 
-la realización de actividades empresariales-, que se desarrolló desde finales del siglo XIX y, sobre todo, tras la primera guerra mundial ${ }^{32}$.

Esta mayor intensidad de la actividad prestacional de la Europa posguerra, en la industria eléctrica, se enmarcó en un contexto de reconstrucción nacional que llevaron a cabo los países europeos, tras los desastres producidos por las dos guerras mundiales ${ }^{33}$.

En cuanto al desarrollo doctrinario del concepto y el contenido de la noción de servicio público en sus inicios, Duguit señala que el servicio público era "toda actividad cuya realización debe ser regulada, asegurada o controlada por los gobernantes, porque es indispensable para la realización o el desenvolvimiento de la interdependencia social y que es de tal naturaleza que no puede ser asegurada completamente sino mediante la intervención de la fuerza gobernante" 34 .

Esta originaria concepción de servicio público entrega una herencia a la institución que pervive hasta hoy, que sería a juicio de Bermejo Vera, la idea de "reconducción de un sector de actividades socio-económicas a la órbita del poder público, con un marcado carácter instrumental, por cuanto, al margen del distinto régimen jurídico por que se opte, lo que se pretende es imponer la obligatoriedad de la prestación y la regularidad y continuidad en la misma, así como reafirmar los poderes de la Administración pública titular del servicio" 35 .

La actividad eléctrica en sus comienzos, no solo cumplía con los requisitos que señalaba la definición de Duguit antes dicha, para requerir la intervención administrativa necesaria, sino que además, desde temprano, fue vista como un sector estratégico para el desarrollo industrial de los países ${ }^{36}$.

Un importante efecto de la mayor relevancia que rápidamente adquirió la energía eléctrica para las sociedades, fue que la intervención pública en el sector, que en sus inicios -según hemos visto-, era de predominante ámbito local, pasa a ser principalmente del Estado. Es decir, comienza a decantarse la preeminencia de las prerrogativas estatales en la materia ${ }^{37}$.

\footnotetext{
${ }^{32}$ Santamaría Pastor, Juan, cit. (n. 26), pp. 296-297.

${ }^{33}$ Sobre este punto, véase Be rmejo Vera, José, Derecho, cit. (n. 4), pp. 67 ss.

${ }^{34}$ Citado en Muñoz Machado, Santiago, Tratado, cit. (n. 18), p. 54.

${ }^{35}$ Bermejo Vera, José, Derecho, cit. (n. 4), pp. 67 ss.

${ }^{36}$ En este sentido, indica Cameron, Peter, Competition in Energy Markets. Law and regulation in de European Union ( $2^{\mathrm{a}}$ edición, Oxford, Oxford University Press, 2007), pp. 6-7: "In every industrialized country it has been normal practice for governments to involve themselves in the energy business, and especially in the activities of the electricity and gas industries. [...]. These characteristics contributed to a specific model or pattern of government energy industry relations that, with some variations, was dominated in all the industrialized countries for several decades".

${ }^{37}$ Véase Parejo Alfonso, Luciano, Lecciones, cit. (n. 16), p. 566.
} 
El servicio público, por tanto, como función asistencial del Estado sería rápidamente integrado a la naciente legislación del sector eléctrico, creando una nueva relación entre esta industria y el Estado, hasta que la idea de servicio público entrara en crisis en los Estados europeos, a finales del siglo pasado.

De esta forma, puede observarse el Real Decreto español, de 12 de abril de 1924, que en el artículo 1 señalaba: "Se declaran servicios públicos los suministros de energía eléctrica, agua y gas a los abonados de las empresas de distribución, correspondiendo al Ministerio de Trabajo, Comercio e Industria la reglamentación de tales servicios para garantía de la seguridad e interés públicos, sin perjuicio de las demás intervenciones que puedan corresponder a otros Departamentos, a las Provincias y al Municipio sobre las concesiones y contratos administrativos" 38 .

La declaración como servicio público del suministro de electricidad tenía una clara finalidad instrumental: imponer, formalmente, de una vez por todas, y ante la inobservancia de disposiciones anteriores, la obligatoriedad de la prestación y la regularidad y continuidad en la misma, así como afirmar el poder de la Administración.

No obstante, cabe mencionar, que esta declaración de servicio público del aprovisionamiento eléctrico, no significó una asunción formal por la Administración de la titularidad de la actividad, ni que las empresas privadas dejaron de realizarla. El objetivo, en esta primera etapa del servicio público en el sector eléctrico era meramente pragmático: ejercer un mayor control sobre el mismo ${ }^{39}$.

El Estado prestacional, por tanto, promovió una expansión de la competencia estatal inicial. Comienzan a perfeccionarse los títulos de intervención administrativa, con la exigencia de licencias y autorizaciones para la construcción y funcionamiento de las instalaciones eléctricas. Hubo que esperar bastantes años para que la declaración de servicio público (publicatio) de la actividad de suministro conllevara el apoderamiento por la Administración de funciones de dirección y control sobre las empresas y el sistema eléctrico; dichas funciones se formarán mucho más lentamente y aparecerán progresivamente en la reglamentación que se va elaborando a lo largo del siglo $\mathrm{XX}^{40}$. Sí, en cambio, el servicio público justificaría el desarrollo de la técnica de la planificación en el sector eléctrico.

Tras la primera gran guerra de 1914, y ante la necesidad de dar un impulso a las industrias estratégicas de los Estados europeos, la actividad prestacional del Estado sufre una importante transformación: "Las Administraciones

\footnotetext{
${ }^{38}$ Salas Hernández, Javier, cit. (n. 15), p. 3; PARejo Alfonso, Luciano, Lecciones, cit. (n. 16), p. 566.

${ }^{39}$ Iвíd., pp. 38-39.

${ }^{40}$ Muñoz MaChado, Santiago, Tratado, cit. (n. 18), p. 30.
} 
Públicas asumen la propiedad y la gestión directa de empresas mercantiles y actividades de producción y distribución de bienes y servicios, como es el caso de la energía eléctrica" ${ }^{\prime 1}$.

La experiencia había sido probada con relativo éxito en los gobiernos locales del Reino Unido, donde algunos ayuntamientos realizaron actividad empresarial precisamente en sectores como la producción y distribución de agua, gas y electricidad.

Del mismo modo que evolucionaba la relación entre la Administración y el sector eléctrico, la construcción teórica del servicio público elaborada por la doctrina francesa, también iba aumentando su influencia, especialmente en el Derecho Administrativo de la Europa continental. Una importante ampliación del contenido de la institución puede observarse en la consolidación del Estado empresario.

El servicio público no solo designaba ahora a un conjunto de actividades de naturaleza prestacional realizadas por las entidades públicas, sino que debió adaptarse a una nueva etapa, la del Estado empresario -sometido, por tanto, a las normas del Derecho privado-, y a la asunción de tareas propiamente públicas por parte de organismos privados, con sujeción a las normas de Derecho administrativo.

Un fuerte impulso a la labor empresarial del Estado para las industrias consideradas estratégicas, se realiza precisamente, en la Europa de después de la segunda guerra mundial. La puesta en marcha de políticas públicas de industrialización o reindustrialización, para la reconstrucción de los Estados europeos, significó una asunción plena de la industria energética por las Administraciones.

Francia y Reino Unido, promovieron políticas de nacionalización de las empresas básicas, que siguieron otros países ${ }^{42}$. En este sentido, indica Chick: "On 8 may 1946, the electricity supply industry in France was nationalised and Électricité de France (EDF) was established. In 1947, the Electricity Act nationalised the electricity supply industry in Britain, with 1 April 1948 being set as the "vesting" date for the transfer of assets into central public ownership" 43 .

${ }^{41}$ Santamaría Pastor, Juan, cit. (n. 26), p. 297.

${ }^{42}$ Ibíd., pp. 298-299

${ }^{43}$ CHICK, Martin, Electricity and Energy Policy in Britain, France and the United States since 1945 (Cheltenham, Edward, Legal Publishing Limited, 2007), p. 1. Por su parte, GARNER, John, cit. (n. 12), p. 375, especifica para los casos de Inglaterra y Gales, que con la Electricity Act de 1947 y la Gas Act de 1948, respectivamente: "Gas and electricity supply and distribution have been 'nationalised' and these services are now administered by area boards under the general supervision of independent statutory corporations". 
En este período, integrada la función propiamente pública del Estado con otra más propiamente empresarial, desborda la idea originaria de servicio público. El Estado, como un agente más del ámbito económico privado, realizaba actividades industriales y comerciales. "Actividades que pasaron a formar parte del sector público. Dicha intervención estatal en el proceso económico supuso la aparición de una nueva categoría, admitida pacíficamente por la doctrina y la jurisprudencia: la de los servicios públicos industriales y comerciales, sometidos al Derecho privado" ${ }^{4}$.

Esta estructura, con una Administración asumiendo directamente labores de servicio público en el área energética, construida en connivencia con la reconstrucción de la economía europea posguerra, se asienta principalmente en los procesos de nacionalización de la industria energética liderados por Francia y el Reino Unido.

En este sentido, Francia organizó -entre 1945 y 1946- su industria energética con un modelo de servicio público de prestación directa del Estado, a través de la creación -además de la antes mencionada EDF- de Gaz de France (GdF), Charbonnages de France (CdF) y el Commissariat à l'Energie Atomique (CEA) ${ }^{45}$, que funcionaron de esta forma hasta hace unos pocos años.

Por su parte, el Reino Unido, cuya industria energética nació -como en la mayoría de Estados- como una actividad realizada desde el sector privado, modifico notablemente esta estructura, intensificando la participación estatal en estas empresas, llegando incluso a tomar el control absoluto de algunas de ellas.

En este sentido, señala Dow: "The prevailing view was that the state could best serve the public requirement for energy by itself being the provider-such ownership and control enabled the state to guarantee supply. Accordingly, the coal industry, and the electricity industry, were taken into state ownership" 46 .

En cambio, en Estados Unidos se optó por dejar la actividad energética en manos privadas, intensificándose la regulación de la industria ${ }^{47}$. Sobre

${ }^{44}$ Bermejo Vera, José, Derecho, cit. (n. 4), p. 64.

${ }^{45}$ Cf. Roggenkamp, Martha - Rønne, Anita y otros (editores), Energy law in Europe. National, EU and International Regulation (2a edición, New York, Oxford University Press, 2007), p. 540.

${ }^{46}$ Dow, Stephen, Energy Law in the United Kingdom, en Roggenkamp, Martha - RønNe, Anita y otros (editores), cit. (n. 45), p.1176.

${ }^{47}$ Estados Unidos rechaza la política de nacionalización que invade a la Europa posguerra. En cambio, lleva a cabo un proceso de fuerte regulación y control hacia la industria energética, que tendrá relevancia en el futuro Estado regulador, que asoma en el mundo anglosajón desde los años '70 y promueve la liberalización de los servicios 
este punto, expresa Chick: "regulation rather than nationalisation was the chosen means of exercising increased social control over the electricity utilities, and this found its legislative expression in the Public Utility Holding Company Act of $1935^{\prime 48}$.

Estas tres economías establecieron las bases del modelo energético de la época, fundado en estructuras monopólicas verticalmente integradas, que controlaban la actividad eléctrica en sus áreas de influencia (normalmente sus respectivos países) que se estableció desde mediados de los años cuarenta hasta mediados de los años setenta, en lo que los historiadores económicos refieren como "The Golden Age" o "Les Trentes Glorieuses" 49.

En cuanto a la actividad económica en la España de mediados del siglo $\mathrm{XX}$, ésta asume un tejido empresarial público para toda su industria estratégica, incluida la energética, que asume -en palabras de Núñez- una “estatalización encubierta" ${ }^{50}$, con una soterrada pugna entre la industria energética de la época que buscaba mantener una creativa autorregulación y la independencia económica y de propiedad, y el Estado que comenzó a invertir cada vez en obras de infraestructura eléctrica.

Esta convivencia sector privado-sector público se mantuvo como característica del sistema eléctrico español, a pesar de la nacionalización promovida desde el Estado y concretada a principios de la década de los cincuenta ${ }^{51}$.

Por otra parte, y de manera tardía, Italia tomó el camino de la nacionalización en 1962, con la creación del Ente Nazionale per l'Energia Elettrica (ENEL) que asume casi totalmente la explotación del sector eléctrico. La novedad del proceso de publificación del sistema eléctrica italiano es que

públicos económicos, y que se expande a Europa y algunos países de Latinoamérica hasta hoy.

${ }^{48}$ CHICK, Martin, cit. (n. 43), p. 1.

${ }^{49}$ IвÍD., p. 1.

${ }^{50}$ Núñez Romero-Balmas, Gregorio, Empresas de producción y distribución de electricidad en España (1878-1953), en Revista de Historia Industrial, 7 (1995), pp. 39 ss.

${ }^{51}$ En este sentido, cabe tener en cuenta las palabras de MuÑoz MaCHAdo, Santiago y otros Derecho de la regulación económica. Sector energético (Madrid, Iustel, 2009), I, p. 23: "La singular declaración de servicio público del suministro, que procede [en España] del Decreto de 1924 ya citado, no alcanzó nunca al resto de actividades de producción, transporte y distribución. Además nunca supuso la asunción de la titularidad de la actividad por la Administración pública”. Asimismo, un serio análisis de la evolución histórica del sistema eléctrico español puede verse en: NúÑEZ ROMERO-BALMAS, Gregorio, cit. (n. 50), pp. 39-80. Sobre el mismo tema: BEL, Germà - Costas, Antón, La privatización y sus motivaciones en España: de instrumento a política, en Revista de Historia Industrial, 19-20 (2001), pp. 105-132. También véase: LópEZ-IвOR MaYOR, Vicente, La problemática del sector eléctrico, en Revista Aragonesa de la Administración Pública, 34 (2009) 2, pp. 285-304. 
tuvo su base jurídica en la propia Constitución de 1948 que en el artículo 43 integra las empresas que guarden relación con las "fuentes de energía" al proceso de nacionalización que promueve esta norma ${ }^{52}$.

En definitiva, es en este periodo de la evolución de la relación Estadoactividad energética que se plasman las bases del régimen energético propiamente tal, con un sector energético vinculado directamente al Estado (a través de empresas públicas) o con una intensa regulación que permite una amplia intervención administrativa; ambas fórmulas solventadas por la idea de servicio público en su concepción tradicional, que forjaron una actividad organizada en torno a unas pocas empresas verticalmente integradas en constante expansión, que ejercían la actividad como monopolios, a través de una distribución territorial del mercado, y con una fuerte tendencia a autorregularse.

Se trata, por tanto de un periodo de consolidación de la industria energética en los Estados europeos, que se mantuvo hasta finales de los años $90^{53}$, y que es identificado con un modelo de "regulación tradicional: un modelo cerrado, con derechos de exclusiva, con una regulación exhaustiva, con integración vertical de las actividades, y presidido por los principios de planificación conjunta vinculante, explotación centralizada y remuneración en base a costes" 54 .

Este sistema organizativo, de relativamente escasa planificación global por parte de la Administración, se mantuvo statu quo hasta la implantación progresiva -en los años noventa- de las ideas neoliberales que giran en torno al establecimiento del mercado como modelo de asignación de los recursos

${ }^{52}$ Trillo-Figueroa Martínez-Conde, Jesús - López-Jurado Escribano, Francisco, cit. (n. 17), pp.540-541.

${ }^{53}$ Los autores están de acuerdo en situar el punto de partida del proceso de liberalización del sector eléctrico para Europa en el año 1996, momento en que la Comunidad Europea (actual Unión Europea) dictó la Directiva N 96/92/CE, de 19 de diciembre de 1996, sobre normas comunes para el mercado interior de la electricidad, que significó un verdadero cambio de rumbo de las políticas energéticas de los Estados miembros. Es necesario indicar, sin embargo, que Inglaterra ya había iniciado la liberalización de su sector eléctrico algunos años antes, con la Electricity Act de 1989, y que sirvió de referencia al modelo propuesto por la Comunidad Europea en esta Directiva. Sobre esta idea, Fernández García, Yolanda, El concepto jurídico indeterminado de 'servicio esencial en la Constitución española, en Revista de Administración Pública, 170 (2006) 2, pp. 325-338; Trillo-Figueroa Martínez-Conde, Jesús - López-Jurado EsCRIBANo, Francisco, cit. (n. 17), pp. 47 ss.; y FABRA UTRAY, Jorge, ¿Liberalización 0 regulación? Un mercado para la electricidad (Madrid, Marcial Pons, 2004), p. 57.

${ }^{54}$ Ariño Ortiz, Gaspar, Principios de Derecho público económico. Modelo de Estado, gestión pública, regulación económica (2a edición, Granada, Comares, 2001), p. 660. 
energéticos; ideas que constataron el anacronismo de la noción servicio público y la necesidad de adecuar el rol del Estado en la actividad energética.

\section{LA LIBERALIZACIÓN DE LOS SERVICIOS PÚBLICOS Y EL SECTOR ELÉCTRICO: HACIA EL ESTADO REGULADOR Y GARANTIZADOR DE LOS DERECHOS DE LOS CIUDADANOS}

El nuevo orden económico mundial que se vislumbró desde la década de los setenta, y que se hizo dogma -en los ochenta y noventa- con la reorganización del Estado al amparo de las ideas neoliberales de liberalización de los servicios, afectó no solo a los denominados servicios públicos de carácter económico, sino también a la noción de servicio público en general ${ }^{55}$.

Desde esta perspectiva, el Estado de bienestar estático, propio del siglo $\mathrm{XX}$, prestador de servicios públicos, que interviene activamente en la vida de las personas con la finalidad de satisfacer las necesidades básicas de los miembros de la sociedad, y que tiene como principal instrumento administrativo la técnica de la concesión administrativa como modo indirecto de gestión de los servicios públicos; deviene -en palabras de Rodríguez Arana- en un "Estado dinámico de bienestar" 56.

Este se caracteriza por promover el bienestar de los ciudadanos priorizando el rol de Estado garantizador de los derechos fundamentales, entre los que podríamos ubicar el derecho al acceso de los servicios básicos (agua, luz, etc. $)^{57}$.

El servicio público en sentido técnico-jurídico pierde fuerza y validez en favor de nuevos conceptos, categorías e instituciones que nacen precisamente

\footnotetext{
${ }^{55}$ Los autores hablan de crisis del servicio público, derivado de la crisis del Estado de Bienestar. Sobre este tema, véanse: Rodríguez-Arana, Jaime, Servicio público y derecho comunitario europeo, en Revista Catalana de Dret Públic, 31 (2005), pp. 375-397; PARejo Alfonso, Luciano, Servicios públicos y servicios de interés general: la renovada actualidad de los primeros, en Revista de Derecho de la Unión Europea, 7 (2004) 2, pp. 51-68; BERMEJO VERA, José, El régimen de contratación pública en los sectores especiales del agua, la energía, los transportes y los servicios postales, en Revista de Administración Pública, 176 (2008) 2, pp. 115-159; MuÑoz MaCHADo, Santiago, Introducción al sector energético: regulación pública y libre competencia, en MuÑoz MACHADO, Santiago y otros, Derecho, cit. (n. 51), I, pp. 17-51.

${ }^{56}$ Rodríguez-Arana, Jaime, Servicio, cit. (n. 55), pp. 375-397. En el mismo sentido, Muñoz Machado, Servicio público y mercado (Madrid, Civitas, 1998), pp. 74-76.

${ }^{57}$ Estado garantizador de servicios esenciales prestados en competencia, en palabras de Bacigalupo SAgGase, Mariano, Electricidad, servicio público y mercado, en BeCKer, Fernando - SAla, José Manuel y otros, Tratado de regulación del sector eléctrico. Aspectos jurídicos (Cizur Menor, Aranzadi, 2009), I, p 93.
} 
para cumplir cabalmente esta función garantizadora de derechos y libertades ciudadanas, al amparo de una nueva ideología que promueve el desarrollo de actividades de relevancia pública -como la energética- en régimen de competencia ${ }^{58}$.

La emergencia de nuevos conceptos como los de servicio de interés general o servicio de interés económico general, pretenden precisamente conciliar la idea de servicio universal o de obligación de servicio público con la introducción de competencia en sectores estratégicos como el energético.

En este sentido, la idea principal de los servicios de interés económico general es la de distinguir estos servicios de otras actividades que involucran ejercicio de poder público (defensa, justicia, etc.), que por su propia naturaleza no pueden someterse al régimen de libre competencia y mercado. Se trata por tanto, de actividades: $i$ ) prestacionales, que no conllevan el ejercicio de potestades públicas; $i$ i) esenciales, cuya prestación no puede faltar al conjunto de ciudadanos; y iii) de carácter económico ${ }^{59}$.

Por su parte, Bacigalupo indica que con la noción servicio de interés económico general "nace un nuevo servicio público que es fruto de la evolución de un concepto formal-subjetivo (servicio público) a otro material-objetivo (servicio de interés general)" ${ }^{\prime 60}$.

En definitiva, mientras algunos autores argumentan que se ha producido el reemplazo de una institución capital en el desarrollo del Estado desde el siglo XIX, como el servicio público, otros replican que se trata más bien de certificar su adaptación a las nuevas corrientes neoliberales que enseñan al mercado como una alternativa viable para la gestión de ciertos servicios esenciales para la sociedad, retrotrayendo la acción del Estado a la labor de garante del funcionamiento adecuado de los servicios.

Como sea, lo cierto es que ha existido una reestructuración de los servicios públicos de carácter económico, en especial el sector energético -que es el objeto de estudio-, en el sentido de que el mercado, en mayor o menor medida, ha entrado en las distintas legislaciones nacionales; situación que ha

${ }^{58}$ Rodríguez-Arana, Jaime, Servicio, cit. (n. 55), pp. 375 ss.

${ }^{59}$ Véase Laguna de PAZ, José, Servicios de interés económico general (Cizur Menor, Aranzadi, 2009), pp. 34 ss. En el mismo sentido, MARTínez Ló PEZ-MuÑIz, José Luis, en ARIÑo Ortiz, Gaspar (coordinador), Privatización y liberalización de servicios, en Anuario de la Facultad de Derecho de la Universidad Autónoma de Madrid (1999), p. 145, apunta que el concepto de servicio económico de interés general remite a actividades esenciales, cuya prestación no puede faltar a todos los ciudadanos, en adecuadas condiciones de calidad y precio,

${ }^{60}$ Bacigalupo Saggase, Mariano, Electricidad, cit. (n. 57), pp. 87-110. 
producido un proceso de reforma regulatoria, reestructuración, liberalización $\mathrm{y}$, en su caso, privatización del sector eléctrico en los diversos Estados ${ }^{61}$.

Como consecuencia, desde la década de los noventa se viene originando la "reconversión total de la intervención del Estado en la economía para dejar en ella sus posiciones de gestor y retraerse al papel de regulador, quizás no menos comprometido, pero situado sobre el mercado y no en el mercado mismo con sus costes y riesgos" ${ }^{\prime 2}$. Surge, por tanto, una nueva forma de relación Estado-sociedad, en que determinadas actividades de relevancia pública -entre ellas la actividad energética- se realizan en régimen de libertad, de competencia.

En esta nueva relación, el Estado asume un rol promocional y garantizador de los derechos y libertades en general, conservando principalmente la función reguladora para modelar esta libertad económica hacia fines de bienestar de la comunidad, estableciéndose -en palabras de Rodríguez Arana- un principio de libertad solidaria en la prestación de los servicios de interés general ${ }^{63}$.

En este sentido, el servicio público económico energético comenzó a adaptar sus estructuras al nuevo paradigma, introduciendo una profunda reforma de la regulación eléctrica, iniciada por países como Chile, Estados Unidos, Gran Bretaña, Nueva Zelanda, Canadá y Argentina ${ }^{64}$.

Así, en Estados Unidos la liberalización comenzó con la Energy Policy Act de 1992, y más decisivamente después de que California comenzara a explorar opciones de liberalización desde abril de $1994^{65}$, que introduce un nuevo modelo de competencia regulada.

En términos conceptuales, se abandonó la noción de servicio público para la actividad eléctrica, en algunos casos expresamente, como en España lo hizo la actual Ley del sector eléctrico de 1997, cuyo artículo 2.2 señala: "Estas actividades se ejercerán garantizando el acceso y conexión a las redes de

${ }^{61}$ Pérez Arriaga, José - Batlle, Carlos - Vázquez, Carlos, Los mercados eléctricos en Europa, en García Delgado, José - Jiménez, Carlos (directores), Energía: del monopolio al mercado. CNE, diez años de perspectiva (Cizur Menor, CNEAranzadi, 2006), pp. 189-222.

${ }^{62}$ Véase Muñoz MaChado, Santiago, Tratado, cit. (n. 18), p. 1130; CaballeRo SÁNCHEZ, Rafael, Infraestructuras en red y liberalización de servicios públicos (Madrid, Instituto Nacional de Administración Pública, 2003), p. 49.

${ }^{63}$ Rodríguez-Arana, Jaime, Servicio, cit. (n. 55), pp. 375-397.

${ }^{64}$ Ariño Ortiz, Gaspar (director), Energía en España y desafío europeo. Seguridad, concentración empresarial, competencia, regulación (Granada, Comares, 2006), p. 261.

${ }^{65}$ New Bery, David, Refinig Market Design, en Implementing the Internal Market of Electricity: Proposal and Time-Tables (Conferencia Brussels, 2005) [disponible en www.sessa.eu.com]. 
transporte y distribución de energía eléctrica a todos los consumidores del servicio dentro del territorio nacional y tendrán la consideración de servicio esencial"; en otros casos de manera implícita, como en Chile, que sigue estableciendo la idea de servicio público, aunque en la práctica regulatoria del sector se haya desnaturalizado este concepto ${ }^{66}$. Como contrapartida, emergió el concepto de servicio de interés económico general, construcción nacida, como veremos, en la Unión Europea.

El nuevo modelo de competencia regulada, descansa en la doctrina de las "public utilities" de Estado Unidos, donde el rol del poder público es principalmente regulador, y se ejerce a través de Independent Regulatory Commissions $^{67}$.

Al decir de ciertos autores: "El concepto americano de "public utility" trata de establecer un equilibrio entre los intereses de los usuarios que compran y utilizan los servicios y los intereses de las empresas que los producen mediante el establecimiento de unas regulaciones que parten siempre de la libertad de comercio y protegen el acceso a los mercados y la concurrencia" 68

Se pasa entonces, de un Estado prestador del servicio eléctrico a un Estado regulador ${ }^{69}$ y garantizador de los derechos de los ciudadanos, donde los particulares asumen la actividad energética, en régimen de libre competencia, bajo la supervisión y control de entes reguladores autónomos, que velan por el cumplimiento de las obligaciones propias de servicio público por parte de los privados.

Estas obligaciones de servicio público que se imponen por el Estado a los particulares que operan el emergente mercado eléctrico son: suministro

${ }^{66}$ Evans Espiñeira, Eugenio - Seeger Caerols, María, Derecho eléctrico, cit. (n. 2), pp. 4-5. señalan para el caso chileno que: "La actual regulación eléctrica configura el sector eléctrico -de manera global y desde una perspectiva finalista, esto es, considerando su prestación final (el suministro a los clientes), como un 'servicio público' en mano privada. Esto significa la asunción por el Estado de la titularidad sobre esa actividad o quehacer social, en cual si bien se concede su gestión a los particulares, por razones económicas o de buen servicio, la Administración asume poderes de regulación y control del servicio".

${ }^{67}$ De la Cruz Ferrer, Juan, Principios de regulación económica en la Unión Europea (Madrid, Instituto de Estudios Económicos, 2002), pp. 205-206.

${ }^{68}$ Neвот Lozano, José y otros, Competencia y sector eléctrico: un nuevo régimen jurídico (Madrid, Civitas, 1998), p. 16.

${ }^{69}$ Para profundizar sobre la idea del Estado administrativo regulador en un entorno de liberalización introducido en el contexto de la Unión europea, véase: PAREJO Alfonso, Luciano, Las relaciones y delimitación entre regulador independiente y la Administración General del Estado, en Serrano González, Marina - BacigaLupo SAg gese, Mariano (directores), Cuestiones actuales del Derecho de la Energía. Regulación, Competencia y Control Judicial, (Madrid, Iustel, 2010), pp. 59-106. 
continuo y de calidad, acceso universal y a precios asequibles, protección del medio ambiente, entre otros.

\section{LA UNIÓN EUROPEA Y EL SERVICIO DE INTERÉS ECONÓMICO GENERAL.}

\section{SU INFLUENCIA SOBRE EL SECTOR ELÉCTRICO}

La Unión Europea ha tenido un rol esencial en la liberalización del sector energético que ha sido intensa desde la década de los noventa. Asimismo, su reticencia a aceptar en su acervo jurídico la noción de servicio público ha sido decisiva para la transformación de esta institución típicamente francesa ${ }^{70}$. Ambas ideas dan paso a la cristalización de la expresión "servicio económico de interés general” que procede del Derecho de la Unión Europea ${ }^{71}$.

En este sentido, López-Ibor Mayor explica que: “[...] a finales de los años ochenta tiene lugar en el seno de la Comunidad Europea una nueva etapa definida por el propósito de liberalizar las industrias principales de red, que habían sido en su mayoría, publificadas tras la Segunda Guerra Mundial"72.

Por tanto, para introducir la liberalización, la Unión Europea -que rehúye del concepto de servicio público- diseña un régimen jurídico especial, bajo la denominación de servicios de interés económico general, para un conjunto de actividades esenciales para la comunidad, de carácter económico, pero que no conllevan el ejercicio de potestades públicas del Estado, es decir, que se pueden prestar por manos privadas en régimen de competencia. Esta idea

${ }^{70}$ Una de las principales dificultades que ha debido sortear la Unión Europea es la necesidad de armonizar las instituciones jurídicas provenientes del Derecho europeo continental con aquellas propias del Derecho anglosajón. Por ello, en el proceso de liberalización de los servicios económicos esenciales, evito hacer referencia al servicio público, introduciendo la noción de servicio económico de interés general, que armoniza esta institución clásica proveniente del Derecho francés, con la liberalización como fenómeno económico que promueve introducción de libre competencia para los servicios económicos.

${ }^{71}$ Véase Montero Pascual, Juan (coordinador), Financiación de las obligaciones de servicio público. Ayudas públicas a las telecomunicaciones, televisión, correos y transporte aéreo, marítimo y terrestre (Valencia, Tirant lo Blanch-UNED, 2009), pp. 25-28; Ariño Ortiz, Gaspar, Principios, cit. (n. 54), pp. 557 ss.; Martínez López-MuñIz, José, El servicio público. Origen y significación, en IUSTEL [visible en internet: http:// www.iustel.com/v2/c.asp]; RodrígueZ-Arana, Jaime, Servicio, cit. (n. 55), pp. 375397.

${ }^{72}$ López- Ibor Mayor, Vicente, Problemática, cit. (n. 48), pp. 285-304. 
se plasmó en el artículo 86.2 Tratado de la Comunidad Europea (anterior artículo $90.27^{73}$.

Este proceso liberalizador que promueve la Unión Europea ha contribuido a la reformulación (y casi abandono) de la noción de servicio público, que ha sido utilizado como modelo de regulación e intervención de los grandes sectores industriales -energía, telecomunicaciones, transportes, servicio postal, etc.- en la Europa Continental ${ }^{74}$ desde finales del siglo XIX y durante todo el siglo XX.

Como consecuencia, los Estados miembro de la Unión Europea han debido ir adaptando sus estructuras económicas y sus ordenamientos nacionales, reorientando sus construcciones jurídicas, a fin de dar ejecución al modelo diseñado por la Unión Europea; situación que es plenamente aplicable a lo que sucede con el sector eléctrico ${ }^{75}$.

En el ámbito del Derecho de la Unión Europea, los tratados no han asumido ni el término ni la categoría del servicio público. El artículo 222 del "Tratado de Roma" ya proclamó la neutralidad de la Comunidad Europea ante la propiedad y el estatuto público o privado de las empresas. Por su parte, el artículo 90.2 del Tratado de la Comunidad Europea contemplaba a "las empresas encargadas de la gestión de servicios de interés económico general", sometiéndolas a las normas del Tratado y, en especial, a las disposiciones sobre la competencia.

Sin embargo, ante el importante proceso de liberalización de los servicios de comunicaciones, transporte y energía impulsado por la Comisión Europea durante los años noventa, se erigió una contraofensiva de la "ideología del servicio público" favorable al mantenimiento de sus prerrogativas tradicionales, liderado por Francia.

Para aclarar términos, conceptos y realidades, la Comisión aprobó el 11 de septiembre de 1996 la Comunicación sobre los servicios de interés general

${ }^{73}$ Sobre esta idea, véase Laguna Laguna de Paz, José, cit. (n. 59); Maillo González, Orús, Servicios de interés general y artículo 86 del Tratado CE: una visión evolutiva, en Serie de documentos de trabajo (Madrid, Instituto de Estudios Europeos de la Universidad San Pablo-CEU, 2005), pp. 1-49. [visible en internet: http://www.idee. ceu.es $/$ access.php?file $=/$ secure $/$ docs $/$ publicaciones $/$ DocumentosTrabajo/Jero\%20 competencia\%201-05II.pdf].

${ }^{74}$ López-Ibor Mayor, Vicente, La liberalización del Sector eléctrico: perspectiva jurídica, en Revista española de Derecho Administrativo, 98 (1998) 2, pp. 191-210.

${ }^{75}$ Un claro ejemplo de esta idea la observamos en la progresión de la normativa eléctrica española. Así, mientras la Ley $N^{\circ}$ 40/1994, de 30 de diciembre, de ordenación del Sistema Eléctrico Nacional, contemplaba en el artículo 2.1 la noción de servicio público, la nueva Ley $\mathrm{N}^{\circ} 54 / 1997$, sustituyó este término por el de "servicio esencial" (artículo 2), para referirse a la obligación de garantizar el suministro eléctrico a todos los "consumidores demandantes" del territorio nacional. 
de Europa ${ }^{76}$, que pretendía esclarecer la confusión de términos existente, distinguiendo conceptualmente entre servicios de interés general, servicios de interés económico general, servicio público y servicio universal ${ }^{77}$.

Otro documento relevante, para conocer la propuesta de la Unión Europea sobre el tema es el "Libro Verde", sobre los servicios de interés general de $2003^{78}$, que expresa: "las divergencias terminológicas, la confusión semántica $y$ las diversas tradiciones existentes en los Estados miembros han provocado no pocos malentendidos en el debate a escala europea. Para describir los servicios de interés general se utilizan en los Estados miembros términos y definiciones diversos, como no podia ser menos si tenemos en cuenta las diferencias históricas, económicas, culturales y politicas que existen entre ellos"79.

Asimismo, aclara el "Libro Verde", que el término "servicio de interés general" no figura en el Tratado; no obstante -continúa, en la práctica comunitaria, deriva de la expresión "servicio de interés económico general" que sí recoge el Tratado (en los artículos 16 y 86.2 TCE.). Implica aquel un concepto más amplio que éste último, ya que abarca los servicios sometidos o no a la disciplina de mercado, que las autoridades públicas consideran de interés general y están sometidos a obligaciones específicas de servicio público $^{80}$.

El mismo documento señala que "los términos de 'servicio de interés general' y 'servicio de interés económico general' no deben confundirse con la expresión 'servicio público', un término más ambiguo que puede tener diversos significados y, por tanto, inducir a confusión. Con esta expresión se alude a veces al hecho de que un determinado servicio se ofrece al público en general, mientras que otras veces lo que se quiere resaltar es que se ha asignado a un servicio una misión específica de interés público o se hace referencia al régimen de propiedad o al estatuto de la entidad que presta el servicio en cuestión" ${ }^{" 1}$. A su vez, la expresión obligaciones de servicio público, alude a "las obligaciones específicas impuestas por los poderes públicos al proveedor

${ }^{76}$ Comunicación que ha sido modificada por la Comunicación "Los servicios de interés general en Europa, de 19 de enero de 2001. La Comunicación de 1996. Se puede conocer el contenido de ambas comunicaciones, así como la definición concreta que estos documentos dan a servicio público, servicio económico de interés general, servicio de interés general y servicio universal en el sitio web de la Unión Europea [visible en internet: http://europa.eu/legislation_summaries/other/l26087_es.htm].

${ }^{77}$ Martínez López-MuÑIz, José, El servicio público, cit. (n. 71), p. 352.

${ }^{78}$ Véase "Libro verde sobre los servicios de interés general, de la Comisión”, de 21 de mayo de 2003, especialmente en el punto 1.1 Definiciones y terminología, parágrafo 15, p. 7.

79 "Libro verde", cit. (n. 75), parágrafo 15, p. 7.

${ }^{80}$ Véase "Libro verde", cit. (n. 75), parágrafo 16, p. 7.

${ }^{81}$ Véase "Libro verde", cit. (n. 75), parágrafo 19, p. 8. 
del servicio con el fin de garantizar la consecución de ciertos objetivos de interés público, por ejemplo en materia de transporte aéreo, ferroviario o por carretera, o en el sector de la energía" $" 2$.

Finalmente, el concepto de servicio universal -señala el "Libro Verde""designa un conjunto de requisitos de interés general que garantizan que ciertos servicios se ponen a disposición, con una calidad especificada, de todos los consumidores y usuarios en todo el territorio de un Estado miembro con independencia de su situación geográfica y, en función de las circunstancias nacionales específicas, a un precio asequible" (parágrafo 50, p. 17).

Ha sido labor de la jurisprudencia comunitaria la determinación de algunas ideas básicas sobre la regulación de los servicios de interés general, ante la ausencia de los Tratados constitutivos ${ }^{83}$. En este sentido, el Tribunal de Justicia de la Unión Europea ha establecido la validez del principio de subsidiariedad para la concreción de una definición de los servicios de interés general, es decir, ante el silencio de las normas comunitarias, corresponderá a los Estados la imposición de obligaciones que den contenido a esta noción.

Esta elaboración jurisprudencial ha sido posteriormente ratificada por las normas comunitarias y el Tratado de Lisboa, que entró en vigor en 2009. En este sentido, dicho Tratado, en su "Protocolo sobre los servicios de interés general”, reconoce la amplia capacidad de discreción de las autoridades nacionales, regionales y locales para prestar, encargar y organizar los servicios de interés económico general ${ }^{84}$.

Veremos ahora la aplicación de estas ideas en el sector eléctrico, por ser objeto de nuestro trabajo. Frente a esta compleja nomenclatura conceptual, la Directiva $N^{\circ}$ 96/92/CE, del Parlamento europeo y del Consejo, de 19 de diciembre de 1996, sobre normas comunes para el mercado interior de la electricidad (hoy derogada) ${ }^{85}$, introdujo la idea de que los Estados pue-

82 "Libro verde", cit. (n. 75), parágrafos 21, p. 8.

${ }^{83}$ Véase STJCE de 19.1.1994, C-364/92, SAT Fluggesellschaft v. Eurocontrol; STJCE de 18.3.1997, C-343/95, Diego Cali \& Figli Srl v. Servizi ecologici porto di Genova SpA; STJCE de 26.3.2009, C-113/07 P, Selex v. Comisión.

${ }^{84}$ Montero Pascual, Juan (coordinador), cit. (n. 71), pp. 26-27.

${ }^{85}$ En términos breves, se puede decir que el mercado interior de la electricidad es un objetivo de la Unión Europea desde la década de los noventa. Este es el objetivo que se marca la Comunidad europea cuando promueve la liberalización del sector eléctrico a través de la Directiva $\mathrm{N}^{\circ}$ 96/92, es decir, que los diversos mercados nacionales que funcionan en los diversos Estados miembros de la Comunidad puedan fundirse en un gran mercado interior, competitivo y de precios de la electricidad accesibles. Esta primera Directiva que impuso la liberalización del sector eléctrico para los Estados miembros es derogada por la Directiva $N^{\circ} 2003 / 54$, que buscando el mismo objetivo, profundizaba sobre los principios y reglas introducidos por la Directiva pionera, 
den imponer a las empresas eléctricas "obligaciones de servicio público de interés económico general”. Así, refería en el artículo 3.2 de esta Directiva que: "Dentro del pleno respeto de las disposiciones pertinentes del Tratado, en particular su artículo 90, los Estados miembrospodrán imponer a las compañias de electricidad obligaciones de servicio público de interés económico general, que podrán referirse a la seguridad, incluida la seguridad de abastecimiento, a la regularidad, a la calidad y al precio de los suministros, asi como a la protección del medio ambiente; estas obligaciones de servicio público deberán definirse claramente, ser transparentes, o discriminatorias y controlables; dichasobligaciones de servicio público, así como su posible revisión, serán publicadas y comunicadas sin demora a la Comisión por los Estados miembros. Como medio de cumplir con las mencionadas obligaciones de servicio público, los Estados miembros que asi lo deseen podrán establecer una planificación a largo plazo".

No sufrió cambios importantes esta idea original introducida por la Directiva antes vista, con la nueva Directiva $\mathrm{N}^{\circ}$ 2003/54/CE, del Parlamento Europeo y del Consejo, de 26 de junio de 2003, sobre normas comunes para el mercado interior de la electricidad y por la que se deroga la Directiva $\mathrm{N}^{\circ}$ 96/92/CE, que establece en el artículo 3.1 un deber para los Estados miembros: velar porque las empresas eléctricas, de conformidad con su organización institucional y cumpliendo el principio de subsidiariedad, operen con miras a la consecución de un mercado competitivo, seguro y sostenible de la electricidad.

Insiste, de la misma forma que la Directiva anterior, en que la armonía entre el carácter de bien esencial de la energía eléctrica, con la necesidad de liberación progresiva de los mercados nacionales hasta configurar un mercado interior, se logra con la idea de facultar a los Estados a "imponer a las empresas eléctricas, en aras del interés económico general, obligaciones de servicio público" (artículo 3.2), haciendo referencia a los mismos objetivos que la Directiva

poniendo énfasis en la separación de actividades y en el acceso de terceros a las redes de transporte de electricidad. Nuevamente, el perfeccionamiento del régimen jurídico creado por esta norma comunitaria motivó a la Comisión Europea a dictar la Directiva $\mathrm{N}^{\circ} 2009 / 72$, hoy vigente, y que profundizó en las ideas de promover la separación efectiva de actividades eléctricas (generación, transporte, distribución y comercialización) y de acceso de terceros a las redes de transporte. En este contexto, desincentivaba el funcionamiento del sector eléctrico como servicio público, introduciendo la idea de servicios económicos de interés general y permitiendo, en este contexto, la posibilidad de que los Estados miembros pudiesen establecer "obligaciones de servicio público" para que éstos pudiesen garantizar a la comunidad la prestación del servicio por parte de privados en condiciones de continuidad, calidad y precios bajos, necesarios para el correcto funcionamiento del sistema. No debemos olvidar, que incluso en un régimen liberalizado de los servicios económicos, el Estado asume un rol de garante del correcto funcionamiento de éstos. 
anterior, esto es, la seguridad, la regularidad y la calidad del suministro, los precios de la electricidad, y la protección del medio ambiente, incluida la eficiencia energética y la protección del clima.

La última modificación al mercado interior de la electricidad impulsado por la Unión europea, a través de la Directiva $N^{\circ}$ 2009/72/CE del Parlamento Europeo y del Consejo, de 13 de julio de 2009, sobre normas comunes para el mercado interior de la electricidad y por la que se deroga la Directiva $\mathrm{N}^{\circ}$ 2003/54/CE mantiene la estructura general de las normas generales referidas a las obligaciones de servicio público, radicando en los Estados la responsabilidad de que las empresas eléctricas actúen con miras a la consecución de un mercado de electricidad, y facultando a los mismos a imponer a las empresas eléctricas obligaciones de servicio público.

Sin embargo, agrega, a esta estructura general, la idea de que las "obligaciones de servicio público deberán definirse claramente, ser transparentes, no discriminatorias y controlables, y garantizar a las empresas eléctricas de la Comunidad el acceso, en igualdad de condiciones, a los consumidores nacionales" (artículo 3.2). Es decir, introduce el deber de transparencia y no discriminación para los Estados, en cuanto a las obligaciones de servicio público que impongan a las empresas eléctricas. Asimismo, en el artículo 3.3 de esta Directiva, introduce la obligación de los Estados de garantizar a los clientes domésticos el derecho a un servicio universal.

Por tanto, la normativa de la Unión Europea, en las tres Directivas antes vistas, logró consolidar -de modo genérico- las categorías de obligaciones de servicio público que pueden imponer los Estados a las empresas eléctricas que actúen en sus ámbitos territoriales ${ }^{86}: i$ ) seguridad, incluida la seguridad de suministro; $i$ ) regularidad del servicio; $i i i)$ calidad y precio de los suministros; y $i v$ ) protección del medio ambiente, incluidas la eficiencia energética, la energía procedente de fuentes renovables y la protección del clima.

En definitiva, esta idea transformadora del servicio público, promovida desde la Unión Europea -para el desarrollo del mercado interior ${ }^{87}$-, y enquistada en el espíritu del Estado liberal (en su tipo ideal), identificado por la contracción del Estado y la disminución del intervencionismo de los poderes públicos en favor del libre juego de la autonomía individual ${ }^{88}$, ha sido progresivamente desplegada por los Estados miembros.

Esta idea se ha ido plasmando en progresivas modificaciones de los estatutos jurídicos para el sector energético, que van concretando y dando

${ }^{86} \mathrm{Cfr}$. Jones, Christopher, EU Energy Law. The Internal Energy Market (Leuven, Claeys \& Casteels, 2004), I, pp. 117-118.

${ }^{87}$ Bacigalupo Saggase, Mariano, Electricidad, cit. (n. 57), pp. 87-109.

${ }^{88}$ Aragón Reyes, Manuel, Del Estado intervencionista al Estado regulador, en BeCKer, Fernando - SAla, José Manuel y otros, cit. (n. 57), I, pp. 27-47. 
contenido a la noción de obligaciones de servicio público, en el marco de una nueva institución jurídica, el servicio de interés económico general.

Esto ha significado para los Estados miembros la exigencia de adaptar sus estructuras política, económica, jurídica y social, a un régimen de competencia en libre mercado, "introduciendo progresivamente medidas liberalizadoras, que paulatinamente ha determinado el abandono - pero aún de manera inacabada- de las técnicas propias del servicio público" ${ }^{99}$.

Esta adecuación, se produce en favor de una apertura de los mercados eléctricos nacionales hasta lograr la concreción -todavía pendiente- de un mercado interior de la electricidad como objetivo de la política energética de la Unión Europea.

\section{EL SERVICIO ECONÓMICO DE INTERÉS GENERAL Y SU APLICACIÓN EN EL SECTOR ELÉCTRICO DE ALGUNOS PAÍSES}

Como hemos visto, en el ámbito de la Unión Europea, España, a través de la Ley $N^{\circ}$ 54/1997, de 27 de noviembre, que regula el sector eléctrico (LSE), de concepción claramente liberalizadora de la actividad eléctrica, abandona la noción tradicional de servicio público y se inclina (artículo 2.2) por considerar "servicio esencial" todas las actividades eléctricas, modificando así de manera sustancial en su intención la regulación nacional precedente que extendía el ámbito del suministro como servicio público del sistema ${ }^{90}$. Tanto la Ley $\mathrm{N}^{\circ} 54 / 1997$, como su reglamento, Real Decreto $\mathrm{N}^{\circ} 1955 / 2000$, de 1 de diciembre, por el que se regulan las actividades de transporte, distribución, comercialización, suministro y procedimientos de autorización de instalaciones de energía eléctrica, desarrollan en sus textos las obligaciones de servicio público que autoriza la Directiva $\mathrm{N}^{\circ} 2009 / 72$, antes mencionadas.

En Gran Bretaña, pionera en la liberalización de los mercados de la energía desde la década de los ochenta, los mercados energéticos se abren a la competencia a través de la privatización del sector. Antes de la privatización, el sistema energético estaba fundado en el monopolio estatal, a través del Central Electricity Generating Board, para la electricidad, y de la British Gas Corporation, para el gas ${ }^{91}$. La liberalización de los mercados energéticos en Gran Bretaña se ha llevado a cabo a través de la Gas Act de

\footnotetext{
${ }^{89}$ Bacigalupo Saggase, Mariano, Electricidad, cit. (n. 57), p. 92.

${ }^{90}$ López-Ibor Mayor, Vicente, Liberalización, cit. (n. 74), p. 204.

${ }^{91}$ SAINZ MARTín, Álvaro, La acción administrativa en el sector energético en Gran Bretaña, en BECKer, Fernando -SALA, José Manuel y otros, cit. (n. 57), I, pp. 889-
} 912. 
1986 y la Electricity Act de 1989, a las que siguieron la Utilities Act de 2000 y la Energy Act de $2004^{92}$.

En el modelo británico se ha establecido un sistema de licencias que permite a los privados operar en el mercado eléctrico y que son concedidas por el ente regulador del sistema, de carácter privado, el Gas and Electricity Markets Authority (GEMA). La licencia concedida a cada empresa que desee actuar en el sistema eléctrico británico, contiene el catálogo de obligaciones impuestas a sus titulares, entre las que se encuentran aquellas que en la tradición jurídica continental son identificadas como obligaciones de servicio público y que, en el ordenamiento jurídico británico, se configura -en términos generales- en el objetivo esencial de protección del interés de los consumidores ${ }^{93}$.

Por tanto, no existen obligaciones generales de servicio público impuestas para las empresas eléctricas que operan en Gran Bretaña por la legislación energéticas; más bien hay obligaciones específicas para cada empresa, contenidas en la licencia de que es titular, y que dicen relación con la protección de los consumidores. En este sentido, indica Dow: "Perhaps the most surprising issue in the UK approach to the Directive ${ }^{94}$ is that the UK continues to have no specific list of public service obligations. Instead, PSOs are deduced from the license itself in form of the obligations on the network operator and on the licensed participants" 95 .

Por su parte, Francia, mantiene un gran arraigo a la noción de servicio público, al punto de considerarlo casi como un principio estructural del Derecho público francés. Esta lógica llevó a mantener una fuerte intervención estatal en la actividad energética, desatendiendo en un primer momento las directrices fijadas por la Directiva $\mathrm{N}^{\circ}$ 92/96, y manteniendo básicamente la estructura de su industria eléctrica, como monopolio público, establecido en la década de los cuarenta, a través de la nacionalización del sistema eléctrico, concretada con la Ley No 46-628, de 8 de abril de $1946^{96}$.

La imposición, por parte de la Unión Europea, de liberar los mercados energéticos, solo tuvo recepción en el ordenamiento jurídico francés, por medio de la Ley $\mathrm{N}^{\circ}$ 2000-108, de 10 de febrero de 2000, relativa a la moder-

${ }^{92}$ Se ha proseguido esta idea en la siguientes normas: Electricity (Miscellaneaous Provisions) Act 2003, Energy Act 2008, Energy Act 2010 y Energy Act 2011. Todas ellas se pueden consultar en: [http://www.legislation.gov.uk/].

${ }^{93}$ Sainz MARTín, Álvaro, cit. (n. 91), pp. 891-892.

${ }^{94}$ Dow hace referencia a la Directiva $\mathrm{N}^{\circ} 2003 / 54 / \mathrm{CE}$.

${ }^{95}$ Dow, Stephen, cit. (n. 46), pp. 1169-1261.

${ }^{96}$ FERNÁNDEZ DE TROCónIz RoBles, Borja, La acción administrativa en el sector energético en Francia, en Becker, Fernando - SALA, José Manuel y otros, cit. (n. 57), pp. 955-976. 
nización y al desarrollo del servicio público de la electricidad, norma que -tal como se intuye en su título- desatiende la idea de introducir los principios del mercado al viejo concepto de servicio público, a través de la actualización conceptual que conlleva la nueva noción de servicio económico de interés general y se limita a remozar el servicio público, desarrollando el régimen de competencia para el sector, no sin antes reiterar la categoría de servicio público de la electricidad.

Siguiendo esta idea, el artículo 1 de la ley indica: "Le service public de lélectricité a pour objet de garantir l approvisionnement en électricité sur ensemble du territoire national, dans le respect de lintérêt général. [...]. Le service public de l'électricité est organisé, chacun pour ce qui le concerne, par l'Etat et les communes ou leurs établissements publics de coopération".

La especialidad del mercado energético francés, que concentra las actividades de electricidad y gas en EDF y GDF, respectivamente, actualmente sociedades anónimas donde el Estado posee la mayor parte de participación, permite mantener el modelo del sistema eléctrico que se sustenta en la figura del servicio público.

Incluso la reciente reforma al modelo energético, que busca introducir mayor competencia en el mercado eléctrico del país, a través de la Ley $\mathrm{N}^{\circ}$ 2010-1488, de 7 de diciembre de 2010, sobre nueva organización del mercado de la electricidad, obligando a EDF a desprenderse de parte de la generación de energía, no contempla un cambio en el contenido de la consideración de la electricidad como servicio público.

Fuera del ámbito de la Unión Europea, otros Estados han introducido en sus ordenamientos jurídicos energéticos -algunos incluso antes que los Estados miembros- la doctrina de los servicios económicos de interés general, promovida desde la Unión Europea, como medida de transformación del servicio público clásico, que busca actualizar sus postulados, conciliando la exigencia de acceso de servicio universal a determinados servicios esenciales para la comunidad, exigibles al Estado, con la idea de liberalización de los servicios económicos y del mercado como medio idóneo de asignación del recurso eléctrico.

Un caso interesante es el de Chile, cuya "actual regulación eléctrica configura el sector eléctrico [...] como un servicio público en mano privada" ${ }^{7}$, esto es, el Estado asume la titularidad sobre la actividad energética, pero delega o concede su gestión a la iniciativa privada. La actuación del poder público se concreta en la regulación y supervigilancia de la actividad privada, a través de un organismo regulador, la Comisión Nacional de Energía.

${ }^{97}$ Evans Espiñeira, Eugenio - Seeger Caerols, María, Derecho eléctrico, cit. (n. 2), pp. 4-5. 
Este modelo, que introduce el mercado al sector eléctrico, fue implantado a través del Decreto con fuerza de ley No 1 , de septiembre de 1982, del Ministerio de Minería ${ }^{98}$, una interesante norma que establece como servicio público la distribución y el suministro eléctrico, servicio público que puede ser objeto de concesión a privados.

La modificación hecha por la Ley $\mathrm{N}^{\circ} 19.940$ de 2004 al modelo de este Decreto con fuerza de ley $\mathrm{N}^{\circ} 1$ de 1982, incluyó el transporte por sistemas de transmisión troncal y subtransmisión como servicio público, pero mantuvo la figura de la concesión, para permitir su explotación por parte de empresas privadas.

Tal como ya mencionamos, el modelo del sector eléctrico chileno, contempla una industria de tres actividades: la generación de electricidad que se realiza en régimen de libre competencia, donde diversas empresas privadas actúan en el mercado de la generación de electricidad; el transporte y distribución que son considerados servicios públicos, pero cuya prestación realizan los particulares en un régimen de concesión, que les otorga exclusividad para actuar en el territorio de concesión, a cambio de la prestación de un servicio continuo, de calidad y a precios razonables. El Estado asume en este modelo un rol subsidiario, que ejerce principalmente a través de la regulación, que tiene por objeto garantizar la libre competencia, es decir que el mercado funcione correctamente, y proteger a los consumidores.

Finalmente, en Argentina -que también ha adoptado un modelo de liberalización de su sistema eléctrico-, durante los años 1991 y 1992 se crearon un conjunto de normas que articulan el funcionamiento de un mercado eléctrico, dejando atrás el modelo de economía planificada que tenía el sector eléctrico argentino hasta ese momento ${ }^{99}$.

La Ley Marco Regulatorio № 24065/92 fue la encargada de configurar el nuevo mercado energético. En este sentido, caracterizó como servicio público al transporte y distribución de electricidad (artículo 1), permitiendo la competencia en la actividad de generación.

También utilizó la concesión como herramienta del nuevo modelo y se creó el Ente Regulador de la Electricidad, que velaría por el funcionamiento del sistema y por las exigencias de servicio público que se imponen a la actividad.

${ }^{98}$ PIÑa, Carlos, Regulación y funcionamiento del sector energético en Chile, en GARCía Delgado, José - Jiménez, Juan (editores), Energía y regulación en Iberoamérica (Cizur Menor, Aranzadi, 2008), II, pp. 9-37.

${ }^{99}$ FANDiÑo, Ester, Regulación y funcionamiento del sector eléctrico en Argentina, en García Delgado, José - Jiménez, Juan (editores), Energía y regulación, cit. (n. 98), pp. 39-73. 


\section{CONCLUSIÓN}

En definitiva, se puede apreciar que la determinación de las "obligaciones de servicio público" en la noción de servicios económicos de interés general y, por tanto, servicio energético, operados por empresas privadas, incluso cuando tengan mayoría de participación estatal, como el caso francés o el italiano, y que funcionan en régimen de mercado, constituye para el Estado una reserva competencial de carácter eminentemente regulador y garante de los derechos de los ciudadanos, que asume, en esta etapa de la evolución del servicio público eléctrico, la responsabilidad final ante los ciudadanos, del correcto funcionamiento del sistema eléctrico, en aras del objetivo general de bienestar de la comunidad.

Por otra parte, habrá que estar pendiente de la evolución que pueda tener la idea que ha surgido en los últimos tiempos en el país, como reacción a la situación social y judicial adversa de los grandes proyectos de generación de electricidad, Hidroaysén y la Central Castilla, entre ellos, de crear una carretera pública de transporte de electricidad de muy alta tensión, para transmitir la electricidad desde estos centros de producción a los grandes polos de consumo energético del país, que podría modificar esta relación entre servicio público y sector eléctrico para la realidad chilena, en el sentido de trasladar - al menos parcialmente- el sector de transporte de la "muy alta tensión", desde manos privadas a manos del Estado, resurgiendo la institución de servicio público con sus características tradicionales, ya algo en desuso en la realidad pública nacional.

\section{BIBLIOGRAFÍA}

Álvarez Garcia, Vicente; Duarte Martínez, Rafael, Administración Pública y electricidad, (Madrid, Civitas, 1997).

Aragón Reyes, Manuel, Del Estado intervencionista al Estado regulador, en en Becker, Fernando; SAla, José Manuel, et al., Tratado de Regulación del Sector Eléctrico. Aspectos Jurídicos (Cizur Menor, Aranzadi, 2009), I.

Ariño Ortiz, Gaspar (Coord.), Privatización y liberalización de servicios, en Anuario de la Facultad de Derecho de la Universidad Autónoma de Madrid (1999).

AriÑo Ortiz, Gaspar(Dir.), Energía en Españay desafio europeo. Seguridad, concentración empresarial, competencia, regulación (Granada, Comares, 2006).

Ariño Ortiz, Gaspar, Principios de Derecho Público Económico. Modelo de Estado, Gestión Pública, Regulación Económica (2a edición, Granada, Comares, 2001).

Ariño Ortiz, Gaspar; Ló pez de Castro, Lucía, Elsistema eléctrico español:Regulación y Competencia (Madrid, Montecorvo, 1998).

Bacigalupo Saggase, Mariano, Electricidad, servicio público y mercado, en Becker, Fernando; Sala, José Manuel, et al., Tratado de Regulación del Sector Eléctrico. Aspectos Jurídicos (Cizur Menor, Aranzadi, 2009), I. 
BeL, Germà; Costas, Antón, La privatización y sus motivaciones en España: de instrumento a politica, en Revista de Historia Industrial, 19-20 (2001).

Bermejo Vera, José, Derecho Administrativo. Parte especial (7a edición, Cizur Menor, Aranzadi, 2009).

Bermejo Vera, José, El régimen de contratación pública en los sectores especiales del agua, la energía, los transportes y los servicios postales, en Revista de Administración Pública, $176(2008) 2$.

CABALlero SÁNCHEz, Rafael, Infraestructuras en red y liberalización de servicios públicos (Madrid, Instituto Nacional de Administración Pública, 2003).

Cameron, Peter, Competition in Energy Markets. Law and regulation in de European Union (2a edición, Oxford, Oxford University Press, 2007).

CHICK, Martin, Electricity and Energy Policy in Britain, France and the United States since 1945 (Cheltenham, Edward Elgal Publishing Limited, 2007).

Cremades, Javier; Rodríguez-Arana, Jaime, Perspectivas del Derecho de la Energía en España y en la UE, en Santos Rech, Miriam y Cameo Bel, Fernando (Coord.), Derecho de la Energía, (Madrid, WoltersKluwer, 2006).

De la Cruz Ferrer, Juan, La liberalización de los servicios públicos y el sector eléctrico. Modelos y análisis de la Ley 54/1997, (Madrid, Marcial Pons, 2005).

De la Cruz Ferrer, Juan, Principios de regulación económica en la Unión Europea, (Madrid, Instituto de Estudios Económicos, 2002).

Dow, Stephen, Energy law in the United Kingdom, en Roggenkamp, Martha; Rønne, Anita et al. (Edit.), Energy law in Europe. National, EU and International Regulation (2a edición, New York, Oxford University Press, 2007).

Evans Espiñeira, Eugenio y Seeger Caerols, María, Derecho Eléctrico, (Santiago de Chile, LexisNexis, 2006).

FABRA UTRAY, Jorge, ¿Liberalización o regulación? Un mercado para la electricidad (Madrid, Marcial Pons, 2004).

FANDiÑo, Ester, Regulación y funcionamiento del sector eléctrico en Argentina, García Delgado, José; Jiménez, Juan (Edit.), Energía y regulación en Iberoamérica (Cizur Menor, Aranzadi, 2008), II.

FERnÁNDEZ De Trocóniz Robles, Borja, La acción administrativa en el sector energético en Francia, en Becker, Fernando; Sala, José Manuel, et al., Tratado de Regulación del Sector Eléctrico. Aspectos Jurídicos (Cizur Menor, Aranzadi, 2009), I.

Fernández García, Yolanda, El concepto jurídico indeterminado de 'servicio esencial en la Constitución española, en Revista de Administración Pública, 170 (2006) 2.

Fischer, Stanley; Dornbusch, Rudiger; Schmalensee, Richard, Economía, (2a edición, traducción castellana de Luis Toharia y María Esther Tabasco, Madrid, McGraw-Hill, 2005).

García de Enterría, Eduardo; Fernández, Tomás-Ramón, Curso de Derecho Administrativo, (15a edición, Civitas, Madrid, 2011).

Garner, John, Administrative Law (Londres, Butterworths, 1963).

Gimeno Feliú, José, El sector eléctrico como servicio público (Madrid, Civitas, 1994).

González-Varas Ibáñez, Santiago, Tratado de Derecho Administrativo. Derecho Administrativo Económico (Cizur Menor, Aranzadi, 2008), IV.

Jones, Christopher, EUEnergy Law. The internal Energy Market (Leuven, Claeys\&Casteels, 2004), I.

Laguna de Paz, José, Servicios de interés económico general (Cizur Menor, Aranzadi, 2009) 
López-Ibor MAyor, Vicente, La liberalización del Sector eléctrico:perspectiva jurídica, en Revista española de Derecho Administrativo, 98 (1998) 2.

López-IвоR Mayor, Vicente, La problemática del sector eléctrico, en Revista Aragonesa de la Administración Pública, 34 (2009) 2.

Maillo González, Orús, Servicios de interés general y artículo 86 del Tratado CE: una visión evolutiva, en Serie de documentos de trabajo (Madrid, Instituto de Estudios Europeos de la Universidad San Pablo-CEU, 2005) [visible en internet: http://www. idee.ceu.es/access.php?file =/secure/docs/publicaciones $/$ DocumentosTrabajo/Jero\%20 competencia\%201-05II.pdf].

Martín Mateo, Ramón, Nuevo Derecho Energético (Madrid, Instituto de Estudios de Administración Local, 1982)

Martínez López-MuÑIz, José, El servicio público. Origen y significación, en IUSTEL, [visible en internet: http://www.iustel.com/v2/c.asp].

Montero Pascual, Juan (Coord.), Financiación de las obligaciones de servicio público. Ayudas públicas a las telecomunicaciones, televisión, correos y transporte aéreo, marítimo $y$ terrestre (Valencia, Tirant lo Blanch-UNED, 2009.

MuÑoz Machado, Santiago et al., Derecho de la regulación económica. Sector energético (Madrid, Iustel, 2009), I.

MuÑoz Machado, Santiago, Introducción al sector energético: regulación pública y libre competencia, en MuÑoz MaCHado, Santiago et al., Derecho de la regulación económica. Sector energético (Madrid, Iustel, 2009), I.

Muñoz Machado, Santiago, Tratado de Derecho Administrativo y Derecho Público General (3a edición, Madrid, Iustel, 2011), I.

Muñoz Machado, Servicio público y mercado (Madrid, Civitas, 1998).

Nebot Lozano, José et al., Competencia y sector eléctrico: un nuevo régimen jurídico (Madrid, Civitas, 1998).

Nebreda Pérez, Joaquín, Distribución eléctrica. Concurrencia de disciplinas jurídicas (Madrid, Civitas, 1999).

Newbery, David, Refinig Market Design, en Implementing the Internal Market of Electricity: Proposal and Time-Tables (Conferencia Brussels, 2005), Disponible en www. sessa.eu.com.

NúÑez Romero-Balmas, Gregorio, Empresas de producción y distribución de electricidad en España (1878-1953), en Revista de Historia Industrial, 7 (1995).

Parada, Ramón, Derecho Administrativo. Parte General (16 edición, Madrid, Marcial Pons, 2007), I.

Parejo Alfonso, Luciano et al., Manual de Derecho Administrativo (5a edición, Barcelona, Ariel, 1998), I.

Parejo Alfonso, Luciano, Las relaciones y delimitación entre regulador independiente y la Administración General del Estado, en Serrano GonzÁlez, Marina y BACigaL U PO SAG GESE, Mariano (directores), Cuestiones actuales del Derecho de la Energía. Regulación, Competencia y Control Judicial, (Madrid, Iustel, 2010).

Parejo Alfonso, Luciano, Lecciones de Derecho Administrativo. Orden económico y sectores de referencia, (Valencia, Tirant lo Blanch, 2010).

Parejo Alfonso, Luciano, Servicios públicos y servicios de interés general: la renovada actualidad de los primeros, en Revista de Derecho de la Unión europea, 7 (2004) 2.

Pérez Arriaga, José; Batlle, Carlos; Vázquez, Carlos, Los mercados eléctricos en Europa, en García Delgado, José; Jiménez, Carlos (Dir.), Energía: del monopolio al mercado. CNE, diez años de perspectiva (Cizur Menor, CNE-Aranzadi, 2006). 
PIÑA, Carlos, Regulación y funcionamiento del sector energético en Chile, en GARCía DELGADO, José; JimÉnEZ, Juan (Edit.), Energía y regulación en Iberoamérica (Cizur Menor, Aranzadi, 2008), II.

Rodríguez-Arana, Jaime, Servicio público y derecho comunitario europeo, en Revista Catalana de Dret Públic, 31 (2005).

Roggenkamp, Martha; Rønne, Anita et al. (Edit.), Energy law in Europe. National, EU and International Regulation (2a edición, New York, Oxford University Press, 2007).

SAINZ MARTín, Álvaro, La acción administrativa en el sector energético en Gran Bretaña, en Becker, Fernando; SAla, José Manuel, et al., Tratado de Regulación del Sector Eléctrico. Aspectos Jurídicos (Cizur Menor, Aranzadi, 2009), I.

Salas Hernández, Javier, Régimen jurídico-administrativo de la energía eléctrica (Bolonia, Publicaciones del Real Colegio de España, 1977).

SAmuelson, Paul y Nordhaus, William, Economía (13 edición, traducción castellana de Luis Toharia y María Esther Tabasco, Madrid, McGraw-Hill, 1990).

Santamaría Pastor, Juan, Principios de Derecho Administrativo General (Madrid, Iustel, 2004), II.

Trillo-Figueroa Martínez-Conde, Jesús; López-Jurado Escribano, Francisco, La regulación del sector eléctrico (Madrid, Civitas, 1996).

Vergara Blanco, Alejandro, Concepto, elementosy principios del serviciopúblico eléctrico, en Revista de Derecho de la Universidad de Concepción, 212 (2002) 2. 
